\title{
CAUGHT IN AN (ETHNOGRAPHIC) MOMENT: NEGOTIATING RELIGIOUS LOYALITIES IN AND OUT OF THE FIELD
}

By Audrey Prost (Department of Anthropology, University College London)

\section{ABSTRACT:}

This paper examines some of the methodological and ethical dilemmas inherent to fieldwork in communities saturated by religious identification and discourses. I examine the dynamics of fieldwork along the fault lines of reflexivity, when one's own existential ground is challenged and reformed through adopting a position of 'practical empathy' with religious beliefs from which one had previously sought to distance oneself. Central to this is the idea that the "ethnographic moment', i.e. the moment in which the anthropologist rises to meet a revealed problematic encapsulated in a particular instance of fieldwork, may be paralleled to the experience of religious epiphany, whereby embodied and intellectual understanding of phenomena and situation come to merge, producing a totalising understanding of the field and the "afield".

To postmodern sensibilities, few places are as satisfying as Dharamsala. Groups of Tibetan youths linger in Indian-style cinema cafes to watch Chinese DVDs, Tibetan monks huddle along the potholed Temple road as swirling taxis spilling out western Buddhist devotees push them aside, only to be overtaken by the chauffeured jeeps of higher modern monks (kushog dengdus) on their way to 'governmental meetings'. Since its early associations with the Dalai Lama and the Tibetan Government in Exile in the 1960s, the town has developed a thriving tourism industry drawing largely from the attractions of Tibetan culture and Buddhism.

But the Diaspora's conflicting self-presentations are, to most exiles, the fabric of daily life, not rare postmodern juxtapositions. Tibetans must negotiate a complex local and global repertoire of identities: while demonstrating attachment to the preservation of Tibetan culture and religion upon which the future of an eventual Tibetan nation is said to rest, they must also now embrace the values of secular politics in order to fulfil the expectations of foreign donor agencies and political organisations (see Klieger 2002). Nevertheless, contemporary anthropological work among the Tibetan Diaspora suggests that exiles have become prisoners of the paradigm of spirituality, which seeks to define religious identity as the primary marker of Tibetanness. This paradigm homogenises the heritage of Tibetan Buddhism, recasting it to a version more manageable by western devotees, and precluding alternative ways of defining contemporary Tibetan identity (Lopez 1999).

It is suggested that while Tibetans are perceived as forever 'caught in the moment' - or more precisely in the ethnographic present of the orientalising gaze - they have little choice but to collude with it as religious institutions are now the principal conduit for financial aid in the community (via donations to monasteries, funds raised by the Dalai Lama, and individual sponsorships to monks and nuns). This critique thus emphasises the financial interests vested in the growing proselytism of Tibetan spirituality in exile and in the West, and the constructed nature of Tibetan discourses in relation to spiritual heritage. But in order to understand Tibetan attitudes to faith one must, I argue, adopt a middle ground (or if one wishes, a Tibetan $u$ med lam) that does not merely reduce expressions of faith to strategies for political and economic gain, but also accounts for the deeply personal and emotional aspect of belief among exiles. Moreover, I argue that a form of epiphanic experience similar to that generated by religious 
practices in the field was key to my own understanding of the field and, later on, to the resolution of theoretical dilemmas during the writing process.

In this I draw in part on Jon Mitchell's work on the importance of feelings and emotion in the analysis of belief (1997). Mitchell argues that belief is based upon "three different, but related, modes of cognition: the semiotic, which relates to language, or to language-like phenomena; the practical, which relates to forms of embodied knowledge; and the emotional, which relates to people's feelings" (ibid: 79-80). Mitchell further proposes that feelings should be understood as part of integrated mind/body experiences and, furthermore, as cognitive events of the same order as semiotic and practical cognition. As the anthropologist experiences in recalling and reconstructing an 'ethnographic moment' in the aftermath of fieldwork, personal experience, feelings, and social memory are mutually constructed and interpretive. None can be understood in isolation from the other.

In order to investigate the relationship between emotions, belief, and social memory, I turn to an episode of fieldwork which I later came to perceive as a key 'ethnographic' moment. During the summer of 2002 the Dalai Lama gave public teachings on Tsongkhapa's Ngarim Chenmo or 'Secret Stages of the Path' at the main temple in McLeod Ganj. As in previous years, I had awaited the ten-day teachings with anticipation at the effervescence that would animate Dharamsala's otherwise tranquil monsoon season. This feeling of excitement was reinforced by the fact that, rather than sitting in the corner allocated to foreigners who listened to the teachings' translation via their short-wave radios, I would be sitting next to Lhamo, my neighbour from Gangkyi, an elderly Tibetan lady recently arrived from Tibet on pilgrimage. Lhamo had bought her own copy of the text and had been following its prescriptions rigorously in preparation for the initiations that would end the teachings. This, I thought, was an opportunity to share the experience of people whose spiritual life I had so far only understood through the means of intellectual study, or through acts of merit-making in which they were kind enough to let me join in, such as recitations, circumambulations, and trips to local pilgrimage sites. On such occasions it was generally assumed that I had only a superficial interest in Buddhism: I was not a self-professed chos nangpa (Buddhist) like many westerners staying in Dharamsala.

I had come to know Lhamo in the course of interviews about the local use of traditional oracles or mopa. She had come to India on pilgrimage from Lhasa after an oracle had told her that she might not survive the year unless she undertook rigorous spiritual practices. Lhamo had thus become immersed in the pursuit of meritorious activity and had embarked upon a tour of the major pilgrimage sites of India, finally bringing her to Dharamsala. On the last day of the teachings, Lhamo woke me at five o'clock in the morning. She wanted to get up to the temple early because the Dalai Lama was going to be there preparing for the day's initiation before the teachings began. This, she said, would be a chance to see him up close and get his blessing. Lhamo had been waiting for such an opportunity since she arrived from Tibet.

Even with such an early start, we were not alone on the road: shortly after 5:30 elders bent at the waist were climbing up the road to the temple. As we arrived, security guards were already out channelling the crowds. Lhamo and I hung to the backs of people struggling to get through the temple's narrow inner passages. The places usually occupied by foreigners were vacant and we walked straight through to get a glimpse of the inner temple. A group of old ladies were huddled against the wall that separated the outer seating space from the inner room where the Dalai Lama sat praying. I could only hear the sound of the drilbu (ritual bell) and the recitations that were being performed. Meanwhile, Lhamo had done her three prostrations and sat down close to the group of women. As I took my seat behind her, I could see the slow balancing motion of the Dalai Lama reciting the prayer. His face would episodically emerge from behind the pillar, and he assumed a calm and absorbed expression. The women observed the same motion as they thumbed the prayer beads with eyes half closed. I could recognise the recitations for the generation of the Bodhicitta voiced by the Dalai Lama at an accelerated pace. 
The process of generating Bodhicitta (byang chub kyi sems), 'the mind of enlightenment', is usually defined as the wish to attain Buddhahood for the sake of sentient beings, and to practice the six perfections (pha rol tu phyin pa drug): generosity, discipline, patience, diligence, concentration and wisdom. At the 'moment' of meditation, developing Bodhicitta means striving to make one's body, speech and mind (sku, gsung, thugs) 'one' in the resolve to attain enlightenment and to perceive them as inextricably linked.

As I reflected upon what I had learnt during the past ten days of teachings and in previous years of study, I wondered how much of this was shared with the women deeply absorbed in reciting mantras next to me as they absently contemplated the gyrating movements of the Dalai Lama.

The bodyguards crossed the room with buzzing walkie-talkies pushing aside all onlookers, although our small group was left undisturbed by the outer wall. Lhamo turned around to squeeze my arm and said thab yags (thank goodness). She was sobbing, obviously so touched by the proximity of the Dalai Lama that she had even relinquished her usual poise. Utterly gripped, Lhamo turned her back to me again and, knees hurting, I resolved to concentrate on the prayer. This was certainly different from the bookish Buddhism I had known from study, and even from the mechanical acts I had seen and accomplished in Tibetan households (going for khora, emptying the prayer bowls of their water in the morning, etc.), and nothing had prepared me for the emotional charge that followed the prayers that day. The women recited the verses of the Bodhisattva vow, and the words I had previously mouthed mechanically became infused with new significance as I watched their faces inscribed with deep wrinkles of resolution. The feeling of communality and determination to uphold the vows generated by the group of devotees, including the Dalai Lama, was highly contagious. I have often attempted to describe this moment when the mind seemed to swoop through a visual tunnel that traversed lands and bodies of suffering like those vividly described in the description of Tibetan hells and samsaric realms, generating a feeling of overwhelming sadness and compassion for the beings caught in the cycle of rebirth. The generation of this compassion harnessed a strong emotional force; the mind, reflecting on suffering and on its own frailty upon facing it, almost seemed to fold onto itself and dissolve.

The experience was incommunicable. I was trapped in my own prejudice against spiritual experience and by the knowledge that the situation had arisen in pre-structured conditions which strongly encouraged a process of cultural mimesis. Endorsing Toren's argument that no knowledge is ever achieved in an asocial situation, Mitchell suggests that "there can be no difference in kind between knowledge of the physical relations between objects and humans, and knowledge of the magical ones" (ibid: 83). My newly arisen faith had discernible roots in the confluence of my own empathic adherence to Buddhist precepts, in the repeated, embodied practice of merit-making acts, and in the strong feeling of communality which I was led to experience through the pre-ordained sequence of the prayer. Here the semiotic, embodied and emotional were inextricably linked in the construction of the spiritual, then later the ethnographic, moment.

However, objectification of the experience as a predictable outcome of participant observation did not make me dismiss it entirely. Instead, this 'moment' radically affected the way I perceived my informants and their religious practice thereafter. I no longer got annoyed when, sitting on the benches of the circumambulation path, I heard women badmouthing their neighbours or commenting on a passer-by's new expensive shoes. I no longer condemned them as undevout, or sought to resolve the contradictions which a Tibetan youth composing songs had once captured: 'you walk the khora [circumambulation path] every morning, but out of your mouth, only bad words are coming out'. Similarly, high Tibetan monks which I had previously suspected of being driven by money and favours began to bask in an aura of irreproachable goodness as my loyalty to the nangpa, the insiders, grew strong with practice. 
In keeping with dominant local and transnational discourses which often characterised encounters with the Dalai Lama as life-changing experiences, the short period I spent in his presence became a determining personal and consequently 'ethnographic moment', a catalyst for personal change both in and out of the field. I suggest here that the normative potential of the 'moment' was certainly increased by the social and 'professional' sanction given to my spiritual experience in both the local context, where westerners are more or less expected to undergo this kind of 'epiphany', and also in the more distant context of anthropological enquiry, where this was a legitimate excursion from participant observation into the realm of felt experience.

I was undeterred by my informants' assertion that many foreigners who converted to Buddhism suffered from an overwork of their mind's faculties and, as a result, often became mentally ill. In Tibetan physiological understandings, these disturbances manifested themselves somatically as humoral imbalances: foreigners were regularly referred to as rlung tsapo (lit. hot wind), i.e. irritable and short-tempered. Indeed, some became self-proclaimed trulkus (incarnations), a few jumped from buildings or roadsides after having vision of their teacher calling them, while others ingested chemical stimulants in the neighbouring hills of Bhagsunath in an attempt to recover the spiritual experience through sensory simulacrum. By contrast, more studious adepts of Buddhism often affected an ascetic detachment from the town's prosaic spiritual bustle, while many claimed to be interested in 'Buddhism as a thing, a system, a philosophy, but not in Tibetans'. Tibetans, they said, will always be 'disappointing' and never 'live up to their great tradition'.

The abstraction of Tibetan Buddhism from its principal source of contemporary practice, i.e. Tibetan exiles, can be seen as a radical step taken by western devotees to appropriate and recast Buddhism in more manageable terms. Many rejected the Tibetan belief in reincarnation and proclaimed it an unnecessary 'leap of faith' in what was otherwise portrayed as nothing more than a coherent philosophical discourse, an 'age-old wisdom for modern times'. Besides, western adepts also had their key 'moments' of encounter with the Buddhist Other, typically the perception of 'clear light' during meditation, receiving the blessing of a cherished teacher or, like me, a communal experience during public teachings.

Staking a claim to the 'moment', to the experiential, is a trope common to the devotee and the anthropologist, as both the ethnographic and epiphanic authority are founded on the grounds of exclusive experiental knowledge. Knowledge of the Other, be it of ultimate reality or the ethereal anthropological other, can be claimed through experiencing a 'moment' that catalyses meaningmaking and forces it into a social shape, giving rise to the agent's new identity as anthropologist or devotee; or, in my fortunate case, as both.

I elected to distance myself from discourses that posited Buddhism as philosophy rather than as faith, and by adopting what I believed was a more embodied form of religious practice, i.e. the emulation of daily acts of merit-making performed by Tibetans. I began to see walls inscribed with mantras and sacred representations as endowed with some form of symbolic religious power. Again, I find resonance in Mitchell's words: "whether it was reverence to such representations per se, or deference to other's belief in them, I could not say, but I soon began to see them as precious objects charged with some sort of power. Through learning the appropriate modes of behaviour, I began to adopt an appropriate cognition" (ibid: 83-84).

The 'ethnographic' and spiritual moment experienced in the temple was not, however, the end of this process of social learning. While writing about the experience proved impossible, its effects percolated down to my ethnographic notes and later on to the substance of my study. I erased entire sections devoted to the financial networking of 'modern monks', which I now deemed unethical, along with various notes on the controversial Shugden cult, a renegade 
Buddhist movement opposed to the Dalai Lama. This fervour also experienced bouts and lapses during which I alternately deleted and inserted the initials H.H. (His Holiness) before the Dalai Lama's name in all my attempts at writing. Back from the field, I unlearnt wearing the tung ngag prayer beads, which I had become accustomed to thumbing in India. But this was, I knew, not the behaviour of a devout Buddhist; I had seen a Tibetan refugee who had been living in Paris for ten years waiting for me patiently by the gates of the Luxembourg Park thumbing his prayer beads and mumbling mantras, as if he had been transported from a Dharamsala street corner, albeit for the changed décor of French exile. Perhaps I was forgetting it all too quickly.

I thus began to pit the experience of the 'ethnographic moment' as a personal and professional memento against the process of desocialisation and unlearning. Furthermore, the writing process involved privileging of a set of locally legitimate data (the epiphanic experience) and the episodic re-enactment of the original emotion as a medium for remembering and communicating something of the life of Tibetan exiles.

I suggest here that there is a continuum of structured experience between the anthropologist's enactment of the ethnographic moment, the protagonist's participation in and legitimation of the moment as culturally valid, and in the anthropologists' remembrance and commemoration of the moment through writing.

What becomes apparent is that the anthropologist does not own the 'ethnographic moment': the latter exists before and after her and, although it is shaped into a discrete configuration by her intervention, it soon again slips out of reach to be appropriated by Others. What remains is the intention to pinpoint a remembered feeling of interdependence located in the emotional cluster brought about by the 'ethnographic moment'. This interdependence is a structural trope which forms the problematic nexus for the interpretation of data and becomes the anthropologist's key to all future methodological locks, a shibboleth. The initial perception of interdependence, as experienced in this religious moment, permeates onwards normatively and in content through remembrance. Through the process of writing and remembering the spiritual 'ethnographic moment', one retains something of the encounter during which interdependence was first perceived, something of the now embodied imprint of the Other.

\section{BIBLIOGRAPHY:}

Klieger, Christiaan. 2002. The Quest for Understanding the Modern Tibetan Self. In Klieger, C. (ed.), Tibet, Self, and the Tibetan Diaspora: Voices of Difference. Leiden: Brill.

Mitchell, Jon P. 1997. A Moment with Christ: The Importance of Feelings in the Analysis of Belief. The Journal of the Royal Anthropological Institute, 3 (1): 79-94.

Rinpoche, Patrul. 1994. The Words of My Perfect Teacher (Kunsang lama'i shelung). Translated by the Padmakara translation group. San Francisco: HarperCollins.

\section{ABOUT THE CONTRIBUTOR:}

Audrey Prost is a Doctoral Candidate in the Department of Anthropology, University College London. Her research investigates contemporary developments in Tibetan medicine and changing conceptions of health among the exile communities of Himachal Pradesh, Northern India. 